\title{
Passing the torch
}

\section{Mike W. Peng}

Editor-in-Chief

It is with a proud sense of accomplishment that I am sharing with you this last Editorial during my tenure as your Editor-in-Chief. Since January 1, 2007, I have had the honor and privilege of serving as APJM's first Editor-in-Chief who is based outside of Asia. Now, after nearly three years and hundreds of manuscripts, I am pleased to announce my editorial retirement and introduce to you our next Editor-inChief, Professor David Ahlstrom. This Editorial (1) offers some reflections on my experience of editing APJM, (2) reports a few recent developments since my last Editorial (Peng, 2009b), and (3) introduces our next Editor-in-Chief.

\section{Making an "A" journal better}

In 1983, APJM started as the world's first (and at that time only) academic journal dedicated to management research focusing on the Asia Pacific region. In the last several years, there has been a proliferation of new academic journals specializing in this part of the world, including a number of outlets dedicated to more specialized areas such as Chinese management. Although we often hear criticisms about the alleged "irrelevance" of academic research in management, such criticisms do not hold much water in research in this area. Clearly, as the Asia Pacific economies take off and occupy a more central position in the global economy, management research with a focus on the Asia Pacific has significantly expanded and endeavored to keep

I thank all members of my editorial team for their dedication and professionalism. They include Senior Editors (David Ahlstrom, Garry Bruton, Michael Carney, David Chan, Simon Lam, Chung-Ming Lau, John Mathews, Klaus Meyer, Eric Tsang, Steven White, and Chi-Sum Wong), Guest Editors (Shyh-jer Chen, Eric Gedajlovic, Steve Globerman, Yuan Lu, Daniel Shapiro, Xiaohua Yang, and Kuang S. Yeh), and Managing Editors (Yung Hua and Rachel Pinkham). This Editorial benefited from discussions with and comments from David Ahlstrom (incoming Editor-in-Chief).

M. W. Peng $(\bowtie)$

University of Texas at Dallas, P. O. Box 830688, SM 43, Richardson, TX 75083, USA

e-mail: apjmpeng@gmail.com 
up with the realities. That is why we now see more scholars and more journals focusing on the Asia Pacific.

In other words, the competition among journals for high-quality manuscripts and authors has been heating up. If $A P J M$ operated in the relatively tranquil (and some would say "obscure" or "nonmainstream") niche of Asia Pacific management research in the 1980s, APJM now competes with both the most established mainstream journals in our field as well as a host of new start-up outlets that fish in the increasingly crowded Asia Pacific waters for top-notch manuscripts and authors. If there has been one goal during my editorship, it is to make the world's longest running and most prestigious academic management journal that is in Asia, on Asia, and of Asia even better. At the end of 2009, looking back at the past three years of efforts, I am very proud to say that this is a mission accomplished.

By traditional measures, evidence is clear. Our submission number is up (from 167 submissions in 2006 to 237 in 2008). ${ }^{1}$ Our citations are steadily increasing. Our acceptance into the Social Sciences Citation Index (SSCI) Journal Citation Reports in 2008 is a long anticipated but nevertheless significant milestone of APJM's coming of age (Peng, 2009a). Here I want to take advantage of this opportunity to share with you some additional qualitative dimensions of what APJM has been doing.

First, a journal is only as good as its authors, and $A P J M$ is blessed with a large number of dedicated authors. Most encouragingly, four deans published five papers during my tenure:

- Dean Keith Glaister of the School of Management, University of Sheffield, UK, coauthored Dong and Glaister (2007).

- Dean Xinchun Li of the School of Business, Sun Yat-sen University, China, contributed Zhang and Li (2008).

- Dean Yuan Li of the School of Management, Xi'an Jiaotong University, China, published two papers with us: Li and Peng (2008) and Su, Xie, and Li (2009).

- Dean Daniel Shapiro of the Segal School of Business, Simon Fraser University, Canada, coauthored Globerman and Shapiro (2009).

Considering how rare it is for deans to be research active, the fact that the words of four deans in five papers grace the pages of our journal in a short span of three years has set a high bar for other competing journals to reach. The fact that these four deans are from three continents speaks volumes about the global nature of our contributors. Evidently, scholars (and deans) around the world care about APJM. We truly appreciate these deans for leading by example in their support for $A P J M$.

Second, academic journals such as $A P J M$ have a unique and important mission of knowledge exploration (Daft \& Lewin, 2008). Interestingly, as the rigor of Asia Pacific management research increases, more and more papers have become technically elegant and focused almost exclusively on exploitation. To overcome this almost inevitable tendency of exploitation driving out exploration, APJM has used its Perspectives and Reviews sections to foster more exploration. As a result, readers will see more exploitation in regular papers and more exploration in the

\footnotetext{
${ }^{1}$ As of this writing (June 30, 2009), APJM received 163 submissions in the first six month of 2009. The projected annualized number of submissions for 2009 would be 326.
} 
Perspectives and Reviews sections. In other words, APJM has maintained a healthy balance between exploration and exploitation. Since imitation is the best form of flattery, it is interesting to see some of our allied (and competing) journals launch their own Perspectives and Reviews sections, presumably in an effort to bring in more exploration as APJM has done.

Third, while $A P J M$, as alluded to earlier, competes with other journals for highquality manuscripts, there really is no competition for some of the papers in APJM. Specifically, some of our Perspectives and Reviews pieces are so valuable and unique that you are unlikely to see anything similar in other journals. This is because $A P J M$ editors proactively recruited these authors who wrote specifically for APJM. For example, upon my invitation, Geert Hofstede (2007) joined our 25th anniversary celebrations with an article on "Asian management in the 21 st century." Ming-Jer Chen (2009) shared an "insider's odyssey" on competitive dynamics research. Dean $\mathrm{Xu}$ (2009) outlined opportunities and challenges for academic returnees in China. John Dunning and Sarianna Lundan (2008) advocated an institution-based view for research on multinational enterprises (MNEs) - published in December 2008, this was Dunning's very last paper appearing before his death in January 2009. It was both amazing (and of course sad) that Dunning ended his 50-year career with his last words published in APJM, which did not even exist when he started his penetrating research in the late 1950s. Dunning's death literally made it impossible for other competing journals to have him as an author. Overall, these are merely some examples of pieces exploring the frontiers of our profession in the pages of our journal.

Fourth, APJM continues to attract numerous high-quality exploitation papers. An important hallmark of scientific progress is replications. Without replications, a scientific field will find it difficult to advance. While many other journals shy away from replications, APJM has embraced a number of rigorously conducted highquality replications. They foster a deeper and more enriched understanding of key phenomena of interest - for instance, the relationship between organizational slack and firm performance (Ju \& Zhao, 2009; Su et al., 2009).

Finally, during my editorship, APJM has significantly broadened its geographic scope, by holding Special Issue Conferences for the first time in the heartland of China (in July 2007 in Xi'an, sponsored by Xi'an Jiaotong University), in Australia (in December 2007 in Brisbane, sponsored by Queensland University of Technology), in Taiwan (in December 2008 in Kaohsiung, sponsored by National Sun Yatsen University), and in Canada (in October 2009 in Vancouver, sponsored by Simon Fraser University and Western Washington University). These first two Conferences already yielded two Special Issues: "Knowledge Management and Innovation Strategy" edited by Lu, Tsang, and Peng (2008) and "The Varieties of Asian Capitalism" edited by Carney, Gedajlovic, and Yang (2009). Editorial work is proceeding for the other two Special Issues based on the Conferences in Kaohsiung and Vancouver- "Managing in Ethnic Chinese Communities" (edited by David Ahlstrom, Kuang S. Yeh, and Shyh-jer Chen) and "Managing Corporate Governance Globally" (edited by Steven Globerman, Mike Peng, and Daniel Shapiro), respectively. In no small measure, these Special Issue Conferences and the efforts that they spawn on both sides of the Pacific (not just on the Asian side) have made $A P J M$ truly an "Asia Pacific" journal, whereas previously APJM could be 
legitimately labeled an "AJM" with relatively little efforts to emphasize its "P" part and to reach out to colleagues outside of Asia.

\section{Fast online publishing and the second Best Paper Award}

Now two reports on recent developments. First, thanks to our supportive publisher Springer, $A P J M$ has now significantly increased the speed for online publishing of an article. Authors now may expect an accepted article to be typeset within one month and to be published online with a citable DOI number (at http://www. springer.com/10490, go to Online First ${ }^{\mathrm{TM}}$ ) within another month - in many cases, within days. This contrasts radically with the slow pace of publishing at many other journals. An accepted article can expect its appearance in a printed issue in about a year. This is slower than before, in part because of the larger backlog of accepted papers. However, this is still faster than many other journals.

Second, after announcing the winner of the first Best Paper Award (Peng, 2009b), I was pleased to announce the winner of the second Best Paper Award, who received a plaque and a $\$ 1,000$ check (courtesy of Springer) at the $A P J M / A A O M$ reception at the Academy of Management meetings in Chicago in August 2009:

John A. Mathews. 2006. Dragon multinationals: New players in 21st century globalization. Asia Pacific Journal of Management, 23(1): 5-27.

The committee was chaired by Klaus Meyer, Senior Editor and winner of APJM's first Best Paper Award in 2008 (as reported in Peng, 2009b). Another Senior Editor, David Ahlstrom, and I were also members. Based on extensive work on Asia-based MNEs including an earlier APJM paper (Mathews, 2002), Mathews (2006) proposed an alternative framework-linkage, leverage, and learning (LLL). The LLL framework was positioned to differ from Dunning's well-known ownership, location, and internalization (OLI) framework based mostly on MNEs in developed economies. In a commentary on Mathews (2006), Dunning (2006) himself appreciated this new perspective. Research interest in MNEs from emerging economies was strong prior to the publication of Mathews (2006). Such interest has grown exponentially ever since. As scholars around the world struggle to theorize about this different breed of MNEs, Mathews (2006) has provided some much needed guiding light for their efforts. This is exactly the kind of contributions that Asia Pacific management scholars aspire to make and that APJM is interested in publishing-Asia-based, globally relevant. Mathews in fact was one of the first scholars I approached to write exploratory pieces. Obviously I was very proud to present the second Best Paper Award to John. Congratulations, John!

\section{Passing the torch to the next Editor-in-Chief}

I am pleased to pass the torch to my friend and former colleague, David Ahlstrom, as the next Editor-in-Chief, effective January 1, 2009. With a PhD from NYU Stern School of Business, Dave has impeccable academic credentials. He has published numerous articles in leading journals such as the Academy of Management Review, 
Journal of Business Venturing, Journal of International Business Studies, Organization Science, and Strategic Management Journal. Dave has also recently coauthored an interesting new textbook, International Management (Ahlstrom \& Bruton, 2009). An American who hails from New York, Dave has lived and worked in the Asia Pacific for over 20 years, with experiences in Hawaii, Japan, Singapore, and most importantly Hong Kong where he has served on the faculty of The Chinese University of Hong Kong since 1996. In addition, among numerous colleagues with whom I have worked, Dave is one of the most widely read scholars - a crucial attribute for being a knowledgeable and open-minded editor. I trust you will enjoy his "outside-the-box" Perspectives piece in this issue: "Reexamining some management lessons from military history" (Ahlstrom, Lamond, \& Ding, 2009).

At $A P J M$, Dave has made important and multidimensional contributions. He was APJM's second most prolific contributor in the decade between 1997 and 2006 (Pleggenkuhle-Miles, Aroul, Sun, \& Yu, 2007: 474). He previously guest-edited a Special Issue on "Turnaround in Asia" (2004), and is currently a lead editor on a new Special Issue on "Managing in Ethnic Chinese Communities" (with Yeh and Chen, forthcoming in 2010). During my tenure as Editor-in-Chief, Dave has graciously served as a Senior Editor, working with a large number of authors and reviewers. I have every confidence that Dave and the new editorial team he has assembled will take APJM to new heights in the next three years. Carry on, Dave!

As for me, letting go will be hard since editing $A P J M$ has become such a part of my daily routine. In the last decade, I have put in a good deal of time into APJM: first as a member of the Editorial Review Board (2000-2003), then as an Editor (2004-2006), and most recently as Editor-in-Chief (2007-2009). To inject new thinking and new blood into the journal, I believe that it is important that I move on. To prevent potential post-retirement "trauma," Dave kindly asked me to stay involved as Consulting Editor, and I gladly said yes. I will oversee the regular issue manuscripts currently under my care, finish the Special Issue on "Managing Corporate Governance" with Globerman and Shapiro based on our Vancouver conference in October 2009, and handle any special task that Dave thinks that I may be of assistance. In closing, if there is one point that I want the APJM community to remember what I have advocated during my tenure as your Editor-in-Chief, it would be a message that I want everybody to tell colleagues, deans, and students: "APJM is an A journal."

\section{References}

Ahlstrom, D., \& Bruton, G. D. 2009. International management: Strategy and culture in the emerging world. Cincinnati: South-Western Cengage Learning.

Ahlstrom, D., Lamond, D., \& Ding, Z. 2009. Reexamining some management lessons from military history. Asia Pacific Journal of Management, 26. DOI: 10.1007/s10490-009-9155-2.

Carney, M., Gedajlovic, E., \& Yang, X. 2009. Varieties of Asian capitalism: Toward an institutional theory of Asian enterprise. Asia Pacific Journal of Management, 26: 361-380.

Chen, M.-J. 2009. Competitive dynamics research: An insider's odyssey. Asia Pacific Journal of Management, 26: 5-26.

Daft, R., \& Lewin, A. 2008. Rigor and relevance in organization studies: Idea migration and academic journal evolution. Organization Science, 19: 177-183.

Dong, L., \& Glaister, K. W. 2007. National and corporate culture differences in international strategic alliances: Perceptions of Chinese partners. Asia Pacific Journal of Management, 24: 191-205. 
Dunning, J. H. 2006. Comment on "Dragon multinational: New players in 21st century globalization." Asia Pacific Journal of Management, 23: 139-141.

Dunning, J. H., \& Lundan, S. M. 2008. Institutions and the OLI paradigm of the multinational enterprise. Asia Pacific Journal of Management, 25: 573-593.

Globerman, S., \& Shapiro, D. 2009. Economic and strategic considerations surrounding Chinese FDI in the United States. Asia Pacific Journal of Management, 26: 163-183.

Hofstede, G. 2007. Asian management in the 21st century. Asia Pacific Journal of Management, 24: 411420.

Ju, M., \& Zhao, H. 2009. Behind organizational slack and firm performance in China: The moderating roles of ownership and competitive intensity. Asia Pacific Journal of Management, 26. DOI: 10.1007/ s10490-009-9148-1.

Li, Y., \& Peng, M. W. 2008. Developing theory from strategic management research in China. Asia Pacific Journal of Management, 25: 563-572.

Lu, Y., Tsang, E. W. K., \& Peng, M. W. 2008. Knowledge management and innovation strategy in the Asia Pacific: Toward an institution-based view. Asia Pacific Journal of Management, 25: 361-374.

Mathews, J. A. 2002. Competitive advantages of the late mover firm: A resource-based account of industrial catch-up strategies. Asia Pacific Journal of Management, 19: 467-488.

Mathews, J. A. 2006. Dragon multinationals: New players in 21st century globalization. Asia Pacific Journal of Management, 23(1): 5-27.

Peng, M. W. 2009a. APJM is now in SSCI. Asia Pacific Journal of Management, 26: 1-3.

Peng, M. W. 2009b. APJM's first Best Paper Award. Asia Pacific Journal of Management, 26: 185-186.

Pleggenkuhle-Miles, E., Aroul, R., Sun, S. L., \& Yu, Y.-S. 2007. The adolescence of Asia management research: APJM, 1997-2006. Asia Pacific Journal of Management, 24: 467-489.

Su, Z., Xie, E., \& Li, Y. 2009. Organizational slack and firm performance during institutional transitions. Asia Pacific Journal of Management, 26: 75-92.

$\mathrm{Xu}$, D. 2009. Opportunities and challenges for academic returnees in China. Asia Pacific Journal of Management, 26: 27-36.

Zhang, S., \& Li, X. 2008. Managerial ties, firm resources, and performance of cluster firms. Asia Pacific Journal of Management, 25: 615-633.

Mike W. Peng (PhD, University of Washington) is the Provost's Distinguished Professor of Global Strategy at the University of Texas at Dallas. As Editor-in-Chief, Professor Peng has recruited talented editors and authors, launched a Best Paper Award, and worked with colleagues to convene Special Issue Conferences in Brisbane, Singapore, Taipei, Vancouver, and Xi'an in an effort to expand APJM's reach around the Asia Pacific. At various forums around the world, Professor Peng has told everyone that APJM is an "A" journal-we start with "Asia," that is clearly an "A." In part because of his efforts to raise its global profile, APJM was accepted by the Social Sciences Citation Index (SSCI) in 2008. 